\title{
Emission reduction of mobile machines by hydraulic hybrid
}

\author{
Seppo Tikkanen, Elias Koskela, Ville Ahola, Kalevi Huhtala \\ Tampere University of Technology \\ Laboratory of Automation and Hydraulic Engineering \\ Korkeakoulunkatu 6 \\ Tampere, Finland \\ E-mail: seppo.tikkanen@tut.fi
}

\begin{abstract}
Emission regulations of the mobile machines have created lot of work for the machine manufacturers in recent years because of the Stage 4 /Tier 4 final regulations. The work will continue because the new EU stage 5 emission regulations for non-road-mobile-machines was published at the year 2016. Emission reduction is realized by different emission reduction systems that are located in the exhaust system in combination with sophisticated combustion control. The after treatment systems increase complexity and size of the exhaust system. Increased creation of NOx and particle emissions are related to sudden load and speed changes of the engine. This paper introduces effect of driving style on the real emissions of the municipal tractor and solutions to decrease emissions with hydraulic hybrid. Measurements show that the sudden load changes increase raw NOx and particle emissions (non after-treated emissions) and operators driving style has effect on the emissions. Stabilizing the load of the engine by the hybrid system reduces NOx and particle generation. When the engine load variation is minimized the size of the exhaust after treatment systems can be reduced.
\end{abstract}

Keywords: non-road mobile machine, exhaust emissions, hydraulic hybrid

\section{Introduction}

The efficiency of the mobile machines has been studied widely during last decade. Lot of effort have been put to reduce fuel consumption and $\mathrm{CO} 2$-emissions. At the same time the exhaust emission regulations of the engines in Europe, the USA and Japan have become more and more strict and reduced emissions of new mobile machines. The emission regulations limit emission of hydrocarbons $(\mathrm{HC})$, carbon monoxide (CO), nitrogen monoxide (NOx) and particle matter $(\mathrm{PM})$ per produced $\mathrm{kWh}$. However, the regulations limit the emissions of the engines, not the emissions of the machines directly. The validation tests are made for the engine in laboratory conditions with predefined load cycles. The loading cycle of the emission tests are composed of various measured real cycles but still they are laboratory test without variation of real conditions and load cycles [1].

"Volkswagen Gate" and also previously known but partly ignored studies have shown that the real world emissions of cars differ drastically from emissions tested in the laboratory conditions [2]. We can assume that this is also valid for the mobile machines although the test cycle for non-road mobile machine include load and speed changes.

The most critical emissions of diesel engine are nitrogen oxiden, NOx, and particle matter emissions, PM, because they have harmful effect on human health. Both nitrogen oxide and particle emission are limited by regulations and the limiting values have been decreased gradually being now over 20-times lower than in mid 1990s.

Each diesel engine produces nitrogen oxide and particle emissions and their amount varies on engine operation point. Because of this fact, the engine emissions are reduced by additional systems. Nitrogen oxides are reduced by exhaust gas recirculation (EGR) and separate systems like Diesel oxidation catalyst (DOC), selective catalyst reduction (SCR) or NOx storage catalyst (NSC) which are part of exhaust system. Particle emissions are reduced by particulate filters. The size of these systems increase remarkably the size of the 
exhaust system. The size of the after treatment systems are depending on the emission reduction performance and if the raw emission can be reduced, the size of the after treatment systems can be smaller respectively.

NOx and particle emissions are increased when engine load and/or speed are changed rapidly compared to constant load situation [3]. Rapid and continuous changes of engine loading are typical for mobile machines like excavator, forest harvesters, and wheel loaders for example. Secondly, the load and speed changes are depending also on the operator's behavior.

In previous studies by Heidari and Marr [4], Ericson, Westerberg and Egnell [5] and Lindgren[6] have shown that NOx and particulate matter emissions factors are depending on the engine transients.

The first research question is: What are the real emissions of the machine during the operation and how they are depending on the operator's driving style? The second research question is: How much raw emissions (emission before after treatment systems) can be reduced by minimizing changes in engine load and speed? The third research question is: Can the load changes compensated by control means and by hydraulic hybrid?

\section{Emission measurements}

The basic problem of the real emission measurements is the question of representativeness of measurement. The aim of the laboratory measurements is to guarantee reproducibility of test event and results, which is base for the quality assurance. Although the laboratory measurement arrangement ensure reliable measurements, the question is; How well the laboratory measurements represent real working conditions? The second issue is that the standard tests are made for the engine, not for the machine. The engines are used in various machines and applications and the consequence is that the same engine produce different amount of emissions in different applications. However, the measurements of individual machines gives valuable information on real emissions although the generalization of the results is restricted.

The difference between real emissions of cars and emissions during certification tests has widely reported in past years because some car manufacturers have tuned the engine control units to recognize the test situation and changing the parameters in order to reduce emissions. In latest emission regulations, this has been tried to solve by implementing randomly chosen combination of test cycles and real driving measurements for new and used cars.

In the latest European emission regulations for the non-road mobile machines in-use-measurements are introduced. This means that engine manufacturer has to show that their engines fulfill the regulations also in application use as new and used. This regulation concerns only gaseous emissions. [1]

The second problem is the realization of measurements, because the emission measurement system is relatively big in volume and weight. This yields situation that the real emissions of small machines are almost impossible to measure without disturbing the operation of the machine.

\subsection{Measurement system}

The measurement platform consisted of machine and measurement system. The used machine was a municipal tractor Wille 655 that is equipped with $100 \mathrm{~kW}$ diesel engine, hydrostatic driveline and load sensing hydraulics with variable pump for the boom and auxiliary devices. The weight of the machine is $5400 \mathrm{~kg}$ without measurement systems and over $6000 \mathrm{~kg}$ with the PEMS-system. The maximum speed of the municipal tractor is $40 \mathrm{~km} / \mathrm{h}$.

The measurement system was Portable Emission Measurement System (PEMS) by AVL and the PEMS enables measurement of real emission of the machine during the work. Figure 1 shows the Wille-municipal tractor with the PEMS-system assembled on the rear frame above the engine.

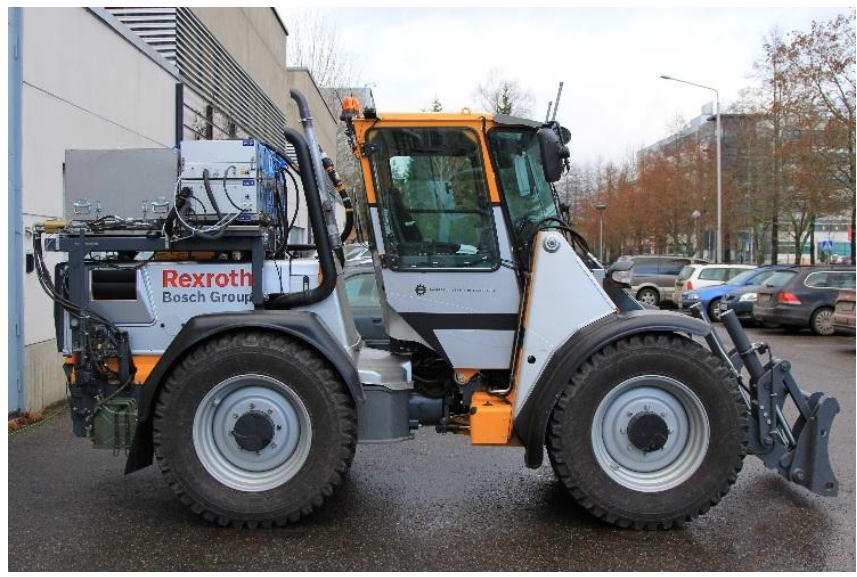

Figure 1: Wille-municipal tractor with the portable emission measurement system.

The emission level of the diesel engine is Tier 3A meaning that limit for combined NOx and $\mathrm{HC}$ emission limit is 4.0 $\mathrm{g} / \mathrm{kWh}$ and $0,3 \mathrm{~g} / \mathrm{kWh}$ for the particulate matter. This engine does not have any particular systems for emission reduction. Currently the new machines have to fulfill Tier 4 final limits that are 10-times lower, respectively $0,4 \mathrm{~g} / \mathrm{kWh}$ for NOx and $0,025 \mathrm{~g} / \mathrm{kWh}$ for Particulate matter at $100 \mathrm{~kW}$ power class. To reach this emission level additional emission reduction systems like, DOC, SCR and DPF are required.

The used portable emission measurement system consists of gas analyzer and particle analyzer and it is able to measure concentrations of total hydrocarbons, THC, nitrogen oxides $\mathrm{NO}$ and $\mathrm{NO}_{2}$, carbon monoxide, $\mathrm{CO}$ and carbon dioxide $\mathrm{CO}_{2}$ and oxygen $\mathrm{O}_{2}$. The particle analyzer consist of soot and particle mass measurement devices. The measurement system included also fuel consumption measurement device and the used fuel was typical "winter type" diesel fuel, which is usable to $-34^{\circ} \mathrm{C}$.

The gas analyzer consisted several analyzers: Flame Ionization Detector (FID) unit for hydrocarbon measurement, Non-dispersive ultra violet resonant absorption spectroscopy (NDUV-RAS) for NOx measurements, Non-dispersive 
infrared spectroscopy for $\mathrm{CO}$ and $\mathrm{CO}_{2}$-measurement and finally $\mathrm{O}_{2}$-sensor to detect oxygen in exhaust.

The measurement system consisted heated sample lines and separate power source (batteries and generator) for the emission measurement system so that the PEMS would not create additional load to the engine.

The engine does not have any exhaust after treatment system and all the measured emissions are raw emissions and not affected by any after treatment system.

\subsection{Test Cycle}

To evaluate the real emissions of the machine different tests were done. Tests included load and carry cycle with two operators having different driving styles.

The tractor was equipped with forks and the load was pallet with metal plates and its weight was 1,5 ton. The load and carry cycle included driving with and without the load. First, the pallet was picked from top of the container and then operator drove about $140 \mathrm{~m}$ and left the pallet on the ground level. This was followed by driving phase, about $280 \mathrm{~m}$ and the pallet was picked again and returned to the initial point, top of the container. The cycle contained $280 \mathrm{~m}$ driving with the pallet and $280 \mathrm{~m}$ driving without the pallet. The route included up- and downhills. The maximum speed was 25 $\mathrm{km} / \mathrm{h}$. The cycle was driven 6 times without stops.

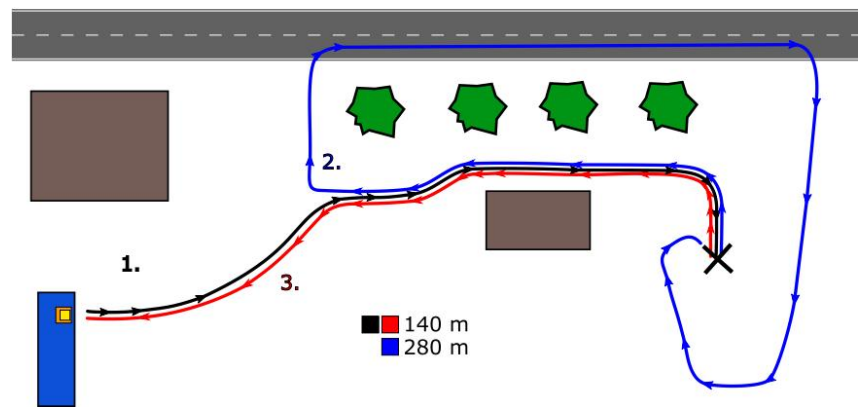

Figure 2: Load and carry cycle route [7].

\subsection{Operators}

To study what is the effect of driving styles of the operator, two operators were used. Both operators drove load-andcarry-cycle. The first operator, operator A had smooth driving style while the second operator, operator B had more aggressive driving style.

\section{Results}

Measurements showed clearly that there is variation in the emissions and the fuel consumption between the operators. Operator A had 22\% higher average power than operator B but fuel consumption was only $10 \%$ higher. Because the used power was higher, the operator A finished the job much quicker: 1715 vs. 1478 seconds. The productivity of operator A was $15 \%$ higher.

Figure 3 shows one load and carry cycle and the time scale is relative time i.e. percentage of total used time for one cycle. There is no major difference on the engine loading or emissions between operators and curves show very similar behavior. The differences are in some operation points. Operator B use maximum loading more often than operator A. The use of maximal power by the operator B is clearly seen at the time of $45 \%$ when the particulate matter and COemissions have peak indicating full fuel amount and lack of fresh air for the combustion.
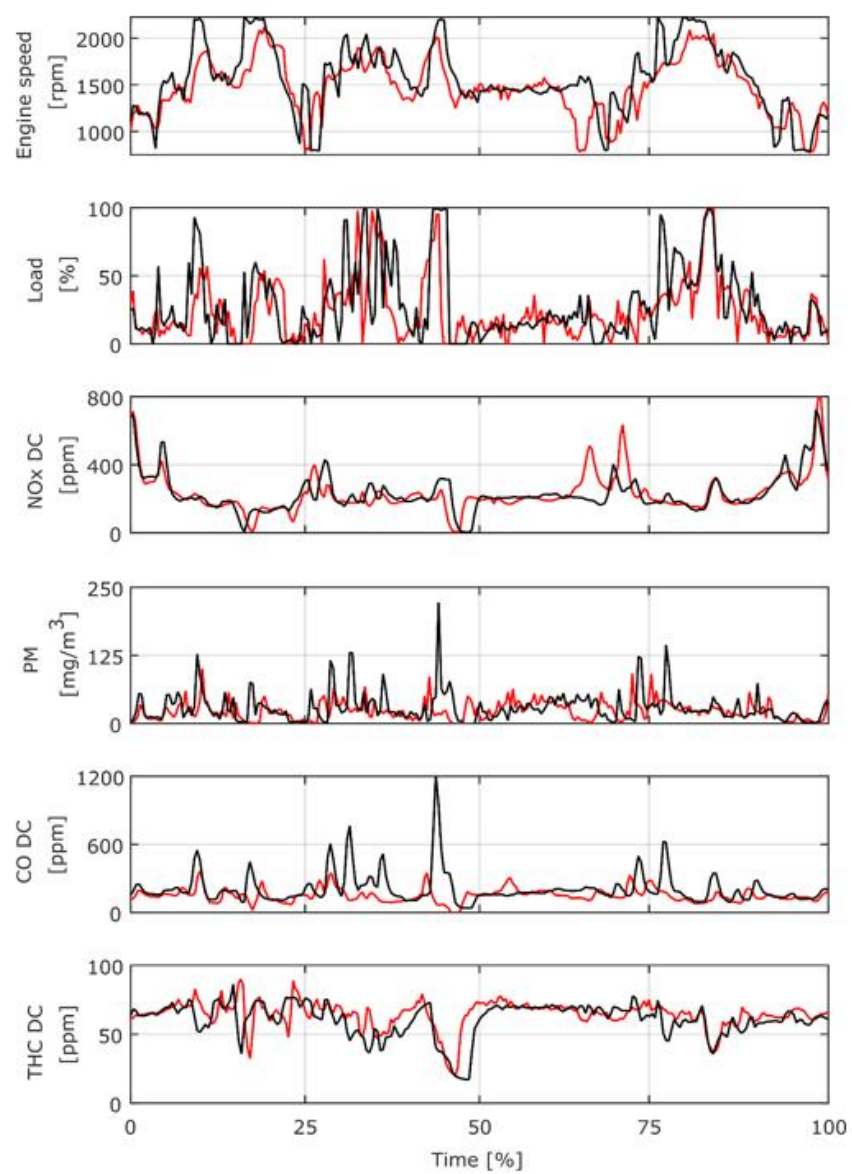

Figure 3: Engine data and emissions for one load and carrycycle. Red line: Operator A, black line: Operator B. [7]

Table 1: Average engine values for the work cycle

\begin{tabular}{|c|c|c|c|c|}
\hline Operator & $\begin{array}{c}\text { Engine } \\
\text { speed } \\
{[\mathbf{r p m}]}\end{array}$ & $\begin{array}{c}\text { Engine } \\
\text { Torque } \\
{[\mathbf{N m}]}\end{array}$ & $\begin{array}{c}\text { Fuel } \\
\text { consumption } \\
{[\mathbf{I}]}\end{array}$ & $\begin{array}{c}\text { Time } \\
{[\mathbf{s}]}\end{array}$ \\
\hline $\mathrm{A}$ & 1479 & 99 & 2,90 & 1715 \\
\hline $\mathrm{B}$ & 1575 & 114 & 3,18 & 1478 \\
\hline
\end{tabular}

Operator B was more productive because he was remarkably quicker in work but at the same time, he consumed more fuel.

Table 2: Exhaust emissions for the work cycle

\begin{tabular}{|c|c|c|c|c|}
\hline Operator & $\begin{array}{c}\mathbf{N O x} \\
{[\mathbf{g} / \mathbf{k W h}]}\end{array}$ & $\begin{array}{c}\mathbf{P M} \\
{[\mathbf{g} / \mathbf{k W h}]}\end{array}$ & $\begin{array}{c}\mathbf{C O} \\
{[\mathbf{g} / \mathbf{k W h}]}\end{array}$ & $\begin{array}{c}\mathbf{T H C} \\
{[\mathbf{g} / \mathbf{k W h}]}\end{array}$ \\
\hline $\mathrm{A}$ & 4,86 & 0,30 & 2,34 & 0,41 \\
\hline $\mathrm{B}$ & 4,53 & 0,42 & 3,33 & 0,36 \\
\hline
\end{tabular}


The measurements show that emission level vary according to operator, however results are not such that was expected because the aggressive drive style did not result higher emissions in all cases. The operator B resulted lower NOx emissions although the difference was only 7 per cent. Opposite to the NOx emissions operator B emitted remarkably higher, 40 per cent, particulate matter emissions than operator A. In the CO-emissions, we see same phenomenon and it seems that the PM and the $\mathrm{CO}$ emissions correlate with each other.

The engine of the municipal tractor has rather high NOxemissions at certain low load points during test cycles. The same phenomenon was observed during constant load measurements: At low engine speed range the engine has relatively high specific NOx-emissions that are caused by inadequate mixing of the fuel and air resulting high local temperatures creating NOx. This phenomenon is clearly seen during acceleration phase below $1000 \mathrm{rpm}$.

When the mean emission levels are compared to the Tier 3 limits, we can see that the engine produces in this test more both combined $\mathrm{NOx}+\mathrm{HC}$ emissions and particulate matter emission than the limit value is. Combined $\mathrm{NOx}+\mathrm{HC}$ emissions are 22 / 32 per cent above the limit value and the particulate matter emissions are almost $40 \%$ above the limit value in the case of the operator B.

The mean used power for operator A were $15,5 \mathrm{~kW}$ and respectively for operator $\mathrm{B} 18,8 \mathrm{~kW}$. Compared to the maximum power of the engine that is $100 \mathrm{~kW}$, the mean power level is low. Figures 4 and 5 show loading points of the engine in load and carry -cycle for both operators.

Load points show that engine hardly never operates at the best efficiency area $(1200-1600 \mathrm{rpm} / 300-480 \mathrm{Nm})$. This is due to the automotive-type transmission control algorithm that is not utilizing the best efficiency area effectively. Driving style difference is seen in the load points, operator B uses more maximum engine speed and maximum engine power [7].

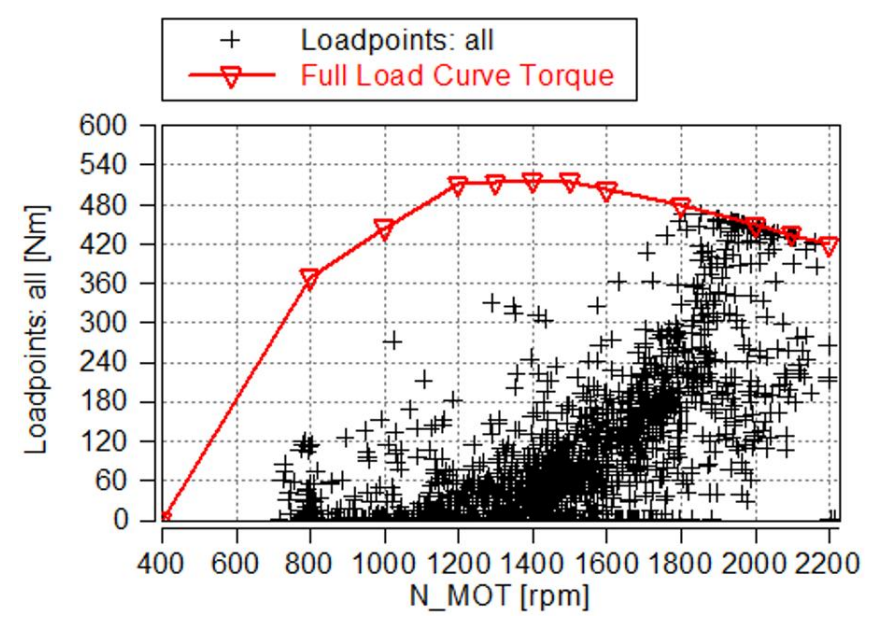

Figure 4: Load points for operator A in load and carry cycle

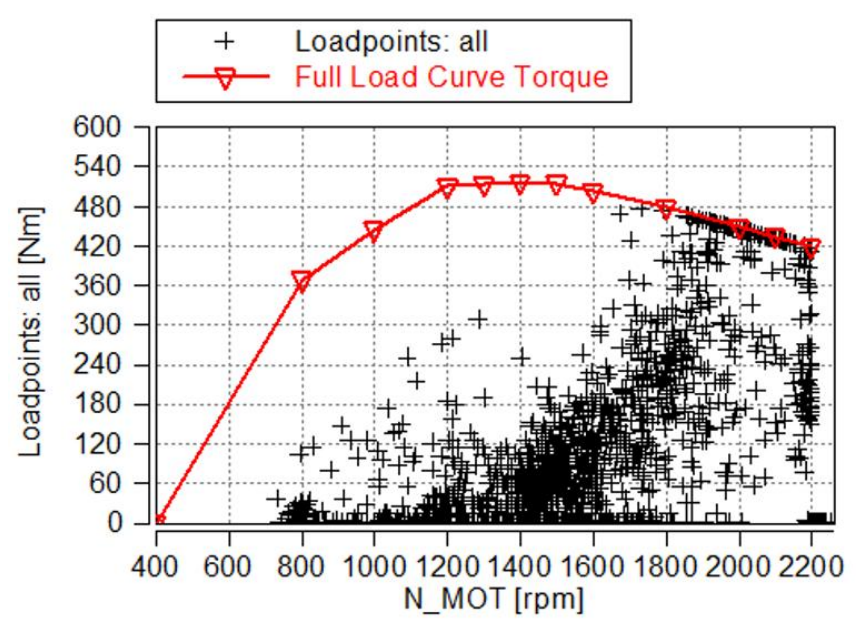

Figure 5: Load points for operator B in load and carry cycle

\section{Emission reduction through hybridization}

Hybrids are usually understood as solution to reduce fuel consumption and the hybrid system is designed accordingly. Hybrid system design can have several other objectives and functions such as boost function; hybrid system provides extra power when needed and enables engine downsizing [8]. Another function is engine load stabilization that is used with engine downsizing but it also can help to reduce the emissions at the same time.

The hypothesis of this study was that by reducing the engine load variation harmful emissions can be reduced. The parallel hybrid system allows engine operate at the mean power level and the hybrid system filters load variation and delivers extra power when needed and stores energy when the load power is below the mean power.

To estimate the effect of the steady state load to the emissions some steady state measurements were made for the machine by loading the implemented hydraulic system by throttling the fluid flow.

If we assume that hybrid system could keep the engine running at the mean operation point, this would mean that load of this engine would be only around $20 \%$ of its maximum. This operation point is far from the ideal for the used engine, because the operation point is not minimizing neither efficiency nor emissions. The emission would be around 4,5 g/kWh for NOx and about $0,65 \mathrm{~g} / \mathrm{kWh}$ for PM emissions. Lower specific consumption and lower specific emissions would require higher engine loading. At the loading point $50 \%$ of maximum at $1500 \mathrm{rpm}$, the emissions would be around $3,2 \mathrm{~g} / \mathrm{kWh}$ for $\mathrm{NOx}$ and $0,25 \mathrm{~g} / \mathrm{kWh}$ for particulate matter. This is remarkably lower than during the test cycles. To move the average operation point towards higher loading requires smaller engine and this is the reason why the smaller engine should be chosen for the hybrid systems. However, both operators used in tests the maximum load at high speed range (Figures 4 and 5) and the hybrid system should provide the power in these operation point if the engine was smaller.

Simple simulation study using measured load power was performed in order to define accumulator size for parallel 
hydraulic hybrid with different load stabilizing goals. The parallel hydraulic hybrid is consisting of an accumulator and over-centre capable variable open circuit pump/motor that is attached to the engine power take-off. The basic control principle of the hydraulic hybrid is the hybrid unit provides the power that equals the load power reduced by the engine power.

$P_{\text {hybrid }}(t)=P_{\text {load_estimation }}(t)-P_{\text {engine_average }}$

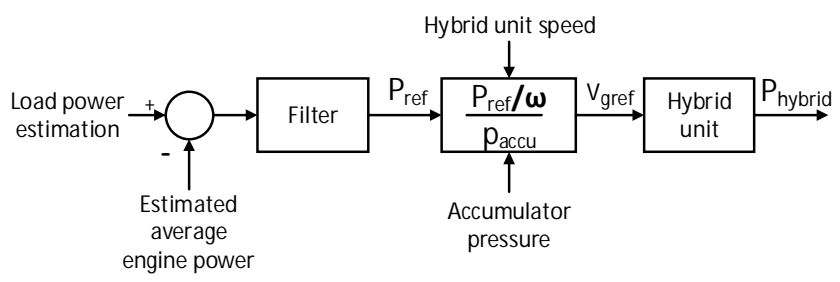

Figure 6: Determination of delivered hybrid power

The determination of the delivered hybrid power is straightforward calculation and the system is open loop control system, and it is accepted that the delivered hybrid power is not exactly accurate. The engine has speed controller and it adapts to the varying load conditions as it does without hybrid assistance. The set value for the engine power is the assumed average power. The load power estimation is calculated from the pressure and the volume flow of the hydraulic pumps and other engine loads. The filter-function eliminates the low frequency load changes of the load estimation, because the goal is to remove rapid load changes by the hydrid unit.

The hybrid unit was modelled using first order transfer function and rate limiter so that the stroke time of from 0 to 100 per cent was $100 \mathrm{~ms}$.

The dimensioning the energy storage for the parallel hybrid system depends on the desired functionality. The hybrid system can be designed to stabilize fully the engine load and then the engine speed and load are nearly constant during the work cycle. For the analysis the recorded load information from the hydraulic systems (including circuits of hydrostatic drivetrain, implemented hydraulics and cooling/steering system) was used and the hybrid system was assumed to handle the load variation. The integration of the calculated hybrid power over time resulted required storage capacity.

Calculation resulted energy storage capacity of $800 \mathrm{~kJ}$ for the studied working cycles and the driving style did not had effect on the storage capacity. To have $800 \mathrm{~kJ}$ as available energy from the accumulator, the required energy should be multiplied by at least 1,25 resulting $100 \mathrm{~L}$ accumulator with 100 bar precharge pressure and 350 bar as maximum pressure level.

The size of accumulator of the hybrid can be reduced if the engine load and the speed are allowed to change moderately. This means that hybrid system is only filtering the rapid load changes and for the studied cycle this results $200 \mathrm{~kJ}$ energy storage capacity and this requires an $30 \mathrm{~L}$ accumulator.
The blue line in Figure 7 shows the case when the hybrid system was designed to compensate fully the load changes of the studied work cycle (storage capacity $800 \mathrm{~kJ}$ ). In this case the engine load was almost constant at $18.5 \mathrm{~kW}$ and hybrid system stabilized the load variation completely. The red line in Figure 7 shows the measured unfiltered load power during one cycle for operator A.

In the case of the moderate load stabilizing and using $200 \mathrm{~kJ}$ storage capacity and the filter was set to pass frequencies higher than $1 \mathrm{~Hz}$. This means that the hybrid system compensates only load transient which frequency is higher than $1 \mathrm{~Hz}$. The black line in Figure 7 shows this case and the curve shows clearly that the high frequency transient are compensated and the peak values of rapid load changes are reduced. This design allows engine load vary quite much, but engine load is more stable than without hybrid unit.

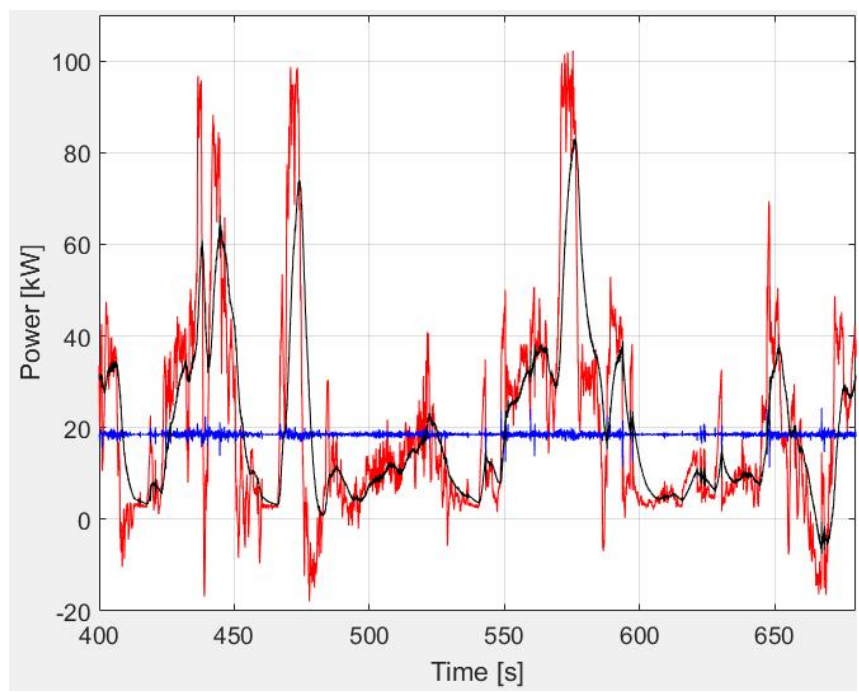

Figure 7: Power curves for different hybrid designs. Load power: Red line, Full stabilized engine load: Blue line, Moderately stabilized engine power: Black line.

The moderate hybrid design can filter rapid load changes. Hagena et al [3] showed that the change of the rise time of the load transient from $1 \mathrm{sec}$ to $5 \mathrm{sec}$ diminish totally the NOx and PM emission peaks caused by the transients. Therefore, we can say that the moderate design of hybrid storage should reduce both NOx and PM emissions, although it does stabilize the engine load completely.

Remaining question is, how representative the results are and in which cases they are valid. Comparing the earlier results and the results of this study, we can say that emissions are depending on the operators driving style and the real emissions differ from the emissions in the laboratory tests. The dependence of the operator is influenced by many factors, such engine type, after treatment system, machine type, working environment, processed material and operator. Further work is needed to determinate the influence of the mentioned factors and their correlations.

The next step is to realize the moderate hybrid system in machine and perform same tests in order to validate hypothesis in real life. 


\section{Conclusion}

The exhaust emissions of the mobile machines are strongly dependent on the work cycle and the operator. The real emissions during the work are higher than is set in emission regulations because standard tests do not correspond the real conditions.

Amount of the generated harmful emissions NOx and PM are depending on the driving style of operator and especially PM emissions are increasing together with aggressiveness of driving style.

The emissions can be reduced by stabilizing the load fully or partly by hybrid system. The moderate storage design has remarkably smaller accumulator but still has potential to reduce harmful emissions remarkably.

\section{References}

1. EU. 2016. Regulation (EU) 2016/1628, 14.9.2016. On requirements relating to gaseous and particulate pollutant emission limits and type-approval for internal combustion engines for non-road mobile machinery, amending Regulations (EU) No 1024/2012 and (EU) No 167/2013, and amending and repealing Directive $97 / 68 / \mathrm{EC}$

2. Weiss, M., Bonnel, P. Hummel, R., Manfredi, U., Colombo, R., Lanappe, G., Le Lijour, P., Sculati, M. (2011a): Analyzing on-road emissions of light-duty vehicles with Portable Emissions Measurement Systems (PEMS). JRC Technical and Scientific Report 62639, EUR 24697 EN. Ispra, Italy

3. Hagena J.R, Filipi, Z.S., Assanis D.N. 2006. Transient Diesel Emissions: Analysis of Engine Operation during a Tip-In. SAE Paper 2006-01-1151. 2006 SAE World Congress, Detroit April 3-6, 2006

4. Heidari B., Marr L., C., 2015. Real-time emissions from construction equipment compared with model predictions. Journal of the Air\&Waste management Association. 62:2, 115-125, DOI: 10.1080 /10962247.2014.978485

5. Ericson C., Westerberg B., Egnell R., 2005. Transient Emission Predictions with Quasi-Stationary Models. SAE Paper 2005-01-3852. Powertrain Fluid Systems Conference and Exhibition San Antonio, Texas USA October 24-27, 2005.

6. Lindgren M, 2004. Engine Exhaust Gas Emissions from Non-road Mobile Machinery. Dissertation Uppsala University, Acta Universitatis Agriculturae Suecia, Agraria 481. ISBN 91-576-6753-5.

7. Koskela E. 2017. Effects of driving style on the emissions of non-road mobile machinery. Master thesis, Tampere University of Technology. In Finnish.
8. Thiebes, P., 2011. Hybridantriebe für mobile Arbeitsmaschinen - Grundlegende Erkenntnisse und Zusammenhänge, Vorstellung einer Methodik zur Unterstützung des Entwicklungsprozesses und deren Validierung am Beispiel einer Forstmaschine. Karlsruher Institut für Technologie. Dissertation. 2011. ISBN 978-3-86644-808-7 